\title{
Introducción: derechos sociales y la dignidad de la igualdad
}

\author{
Claudio Michelon, Jr. * \\ Universidad de Porto Alegre
}

1. El desarrollo de las instituciones jurídicas en occidente durante las últimas décadas nos ha legado algunos temas cuya discusión es urgente. Esta urgencia es consecuencia del hecho de que los resultados de la discusión tienen implicaciones directas para nuestras prácticas jurídico-institucionales.

En relación a la controversia sobre los derechos sociales, esta urgencia es más aguda tratándose de sociedades que sufren una pronunciada carencia endémica de recursos. Diferentes concepciones de los derechos sociales pueden justificar distintas formas de tomar decisiones políticas sobre el empleo de recursos escasos. Hay numerosos ejemplos para confirmar esta tesis. La concepción de los derechos sociales como derechos sujetivos justiciables ha sido utilizada para fundamentar un gran número de decisiones judiciales recientes en diversos países occidentales y, particularmente, en Latinoamérica. Hace algunos años, un tribunal brasileño decidió que un niño enfermo tiene un derecho social oponible contra el sistema público de salud a un tratamiento médico desarrollado en los Estados Unidos y que tendría un costo de aproximadamente US\$ 163.000,00. El Tribunal le ordenó al Gobierno Federal que costease el tratamiento ${ }^{1}$. El fundamento de esta decisión fue el derecho subjetivo fundamental a la salud, reconocido por la constitución brasileña en su artículo 196.

Ahora bien, en contextos de carencia endémica de recursos, garantizar a tantos cuantos tengan problemas graves de salud un derecho social oponible al gobierno al mejor tratamiento médico disponible tendría un substancial impacto sobre las cuentas públicas y, de hecho, acabaría por otorgar a los

\footnotetext{
* Doctor $(\mathrm{PhD})$ por la Universidad de Edimburgo y Profesor de la Facultad de Derecho de la "Universidade Federal do Rio Grande do Sul".

${ }^{1}$ El fallo del Tribunal de Justicia del Estado de Santa Catarina, Agravo de Instrumento número 1997.000511-3 DOU 13/02/97. La decisión fue posteriormente revocada por el Superior Tribunal de Justiça brasileño, en el Agravo Regimental 183.345.
} 
jueces una competencia jurídica para decidir sobre el destino de una parte considerable de los recursos públicos. El fallo ut supra mencionado puede ser considerado demasiado singular, ya que la enfermedad del niño beneficiado era rara y no es probable que la situación se repita con frecuencia. Pero puede pensarse en otras situaciones más comunes en las cuales la concepción adoptada de derechos sociales podría impactar en decisiones políticas de la comunidad. El Supremo Tribunal Federal brasileño, por ejemplo, ha decidido que todos los que presentan ciertas condiciones médicas graves, como la de ser portador del virus HIV, tienen un derecho subjetivo público a la entrega gratuita de los medicamentos que necesitan para su tratamiento ${ }^{2}$.

Esos ejemplos se repiten cada vez más frecuentemente, en la medida que la tesis de la justiciabilidad de los derechos sociales se torna la nueva ortodoxia del constitucionalismo Latinoamericano. Los artículos que el lector encontrará en esto número de Discusiones debaten los aspectos más importantes de estos controvertidos temas del constitucionalismo contemporáneo.

2. Los derechos sociales nos han sido legados por un conjunto de eventos históricos que no cabe detallar en esta introducción (algunos de los cuales son discutidos por Atria en su texto, y desarrollados por Gargarella en el suyo). No obstante, los conflictos políticos bajo los cuales surgieron los derechos sociales no se quedan en el pasado. Concepciones diversas sobre los derechos sociales tienen implicaciones diversas sobre cómo estructurar nuestras instituciones políticas.

Ahora bien, todos estamos razonablemente familiarizados con objeciones a ciertos usos de los derechos sociales por parte de los teóricos del derecho de tendencia marcadamente conservadora. En particular estos teóricos tienden a negar la justiciabilidad de los derechos sociales. Por otra parte, hay, entre juristas progresistas, una firme tendencia a aceptar que los derechos sociales puedan ser directamente utilizados como fundamento para una decisión judicial.

\footnotetext{
${ }^{2}$ Agravo Regimental 271.283-8, juzgado en 12 de septiembre de 2000.
} 
Atria pretende demostrar, en su artículo, que la implementación concreta de algunos de los ideales más importantes del jurista progresista, en especial la igualdad en la distribución de ciertos tipos de bienes, no puede darse por medio de la efectiva justiciabilidad de los derechos sociales.

3. El argumento presentado por Atria no es empírico: él no esta sugiriendo que hay factores sociales, como la escasez de bienes, que impiden que los derechos sociales sean efectivamente reconocidos a todos los ciudadanos. Obviamente la escasez de bienes es una condición conceptualmente necesaria para cualquiera teoría de la justicia. Lo que Atria intenta demostrar es que hay una incompatibilidad conceptual entre el principio de repartición igualitaria de (al menos ciertos tipos de) bienes y la estrategia de garantizar esta igualdad mediante la atribución de un derecho subjetivo justiciable a estos bienes a todos los ciudadanos.

Esta tesis es contraria, en cierta medida, a la auto-comprensión del liberalismo contemporáneo, que frecuentemente se presenta a si mismo como una teoría política al servicio de la igualdad. Pero el modo particular en que la igualdad es entendida por el liberalismo, según Atria, es diverso del modo en el que la igualdad es entendida por otras tendencias filosófico-políticas. La defensa liberal de la igualdad utilizaría un aparato conceptual diferente al utilizado por otros filósofos. El argumento de Atria en el ensayo que abre esta edición de Discusiones es un intento de demostrar que, de hecho, uno de los conceptos liberales centrales, el concepto de derecho subjetivo, no es capaz de expresar la tesis socialista de que la igualdad es un valor político fundamental, aún cuando es presentado en un ropaje más "igualitarista", como en el caso de los "derechos sociales".

En otras palabras, la tesis de Atria es que la igualdad reclamada por aquellos que no son liberales (por un socialista, o por el mismo Aristóteles) no es la igualdad que teóricos como Rawls y Dworkin reclaman como valor central de sus teorías políticas, dado que seria imposible expresar esa igualdad mas "comprehensiva" en términos de derechos. Aún más: la idea de "derechos sociales" no es capaz de compatibilizar estas ideas.

Algunos teóricos y políticos pensaron que la idea de derechos sociales tendría la potencialidad de permitir que una estructura conceptual esencialmente liberal fuese capaz de canalizar la idea de igualdad por dentro del pensamiento (y del derecho) liberal. Ella permitiría que, por intermedio 
de la distribución equitativa de derechos sociales a los miembros de una comunidad política, pudiésemos al mismo tiempo garantizar la igualdad en la distribución social de bienes y respetar la estructura individualista típica de los conceptos y de las instituciones liberales, cuyo ejemplo mas destacado es el concepto de derecho subjetivo. En otras palabras, que la igualdad fuese implementada sin necesidad de aceptar la idea de que hay vínculos comunitarios diversos de los vínculos mínimos postulados por teóricos políticos liberales.

De hecho, la idea de igualdad es una idea relacional. Su implementación depende de la posibilidad de hacer comparaciones entre los ciudadanos para que los criterios utilizados para distribuir los bienes obedezcan ciertos criterios distributivos. Los derechos subjetivos, por el contrario, son tradicionalmente entendidos como formas de exclusión, del proceso racional de decisión, de consideraciones sobre el bienestar de los demás miembros de la comunidad (son "trumps", para utilizar una expresión típicamente liberal).

4. Para que la novedad de la tesis de Atria sea correctamente apreciada es necesario tener en mente una de sus consecuencias: los tribunales, en la medida en que razonan como tales, es decir sobre la base de derechos sujetivos, no son instituciones aptas para implementar una repartición verdaderamente igualitaria de bienes como la salud, la educación, y otros que son objeto de derechos sociales. Ciertos argumentos comparativos entre personas y situaciones diversas y ciertos conflictos trágicos entre formas alternativas de destinar recursos escasos son obscurecidos por el lenguaje de los "derechos sociales", entendidos como derechos subjetivos.

Esto significa que los tribunales, cuando tratan de decidir casos particulares fundados en la implementación concreta de los "derechos sociales", acaban por excluir del debate "comprehensivo" la decisión sobre la distribución de una significativa parte de los bienes escasos de la comunidad. El debate sobre la distribución de estos recursos quedaría limitado a un órgano que tiene la obligación de decidir con base en formas de raciocinio no comprehensivas, a saber: el poder judicial.

Aquí radica una de las más interesantes características del planteamiento de Atria. Su crítica a la concepción de derechos sociales como derechos justiciables no es simplemente una crítica fundada en el mayor grado de legitimación democrática del poder legislativo, frente al poder 
judicial. Su crítica es más esencial: la forma típica de razonamiento del poder judicial no es la más adecuada para canalizar el debate acerca de la distribución de ciertos bienes escasos

5. Es precisamente aquí donde encontraremos los puntos centrales de desacuerdo entre Atria y sus comentaristas, en especial Bernal y Cruz. Ambos, Bernal y Cruz, creen que es posible llegar a una concepción de los derechos sociales como derechos justiciables.

La clave para que se pueda defender una concepción de los derechos sociales como derechos justiciables es ofrecer, como perciben tanto Bernal cuanto Cruz, una concepción de razonamiento no comprehensivo que pueda ser justificada desde el punto de vista de la filosofía política. Las soluciones que ellos proponen son, bajo ciertos aspectos, semejantes, aunque posean significativas peculiaridades.

Bernal hace un instructivo análisis de diversas formas de concebir los derechos sociales como propiamente jurídicos. Identifica al menos cinco formas diversas de concebir la juridicidad de los derechos sociales (que, en su opinión, está necesariamente ligada a su justiciabilidad). En la parte final de su articulo, defiende una concepción de ellos que debe mucho a la teoría de Alexy sobre los derechos fundamentales. La forma de razonamiento correcta para fundamentar una decisión de aplicación de los derechos sociales sería aquella orientada por la proporcionalidad. La noción de proporcionalidad (y las nociones relacionadas como la de maximización de la eficacia de los derechos sociales) permitiría al juez trascender la forma de razonamiento que es más comúnmente asociada con la actividad judicial fundada en derechos sujetivos privados.

Aquí se encuentran los argumentos de Bernal y Cruz. Cruz sostiene que Atria parte de una concepción demasiado restringida de "derecho subjetivo", que llama "concepción relacional". Con la adopción de una concepción más compleja del derecho subjetivo sería posible para el juez dar cuenta de la mayor complejidad social típica de problemas de justicia distributiva.

A mi juicio ésta es una de las más importantes contribuciones del debate promovido en este número de Discusiones. Aunque Atria, Bernal y Cruz están en radical desacuerdo sobre la justiciabilidad de los derechos sociales, sus argumentos suponen, yo creo que correctamente, que la controversia sobre la justiciabilidad de los derechos sociales no es simplemente una controversia sobre cuáles son los órganos estatales que deben distribuir 
ciertos bienes sociales a los ciudadanos. Es más bien una controversia sobre la naturaleza de los argumentos racionales que se deben emplear para decidir sobre esta distribución. Es obvio que, si no hay un modo racional de decisión que sea propio del juez ( 0 , al menos, del juez de una Corte Constitucional), y que lo diferencie del modo racional "comprehensivo" por medio del cual deciden los parlamentos, la tesis de que las decisiones sobre derechos sociales de los tribunales deben prevalecer sobre las decisiones del Parlamento se hace menos plausible.

6. La naturaleza de la contribución de Gargarella es un poco diversa. Gargarella coincide en línea de principio con la tesis de Atria. Su artículo, sin embargo, ayuda enormemente a comprender algunos de los puntos pendientes del debate.

Gargarella sugiere que el argumento de Atria es válido no solamente en lo que respecta a los derechos sociales. Según él, los derechos sociales son "[e]1 ejemplo que utiliza Atria para llevar adelante su tesis...". Al decirlo, Gargarella llama nuestra atención al hecho de que el argumento de Atria puede ser aplicado más allá del campo de investigación de los derechos sociales. Su articulo propone que la discusión de fondo en el argumento de Atria es la progresiva usurpación de la política por el derecho, algo sobre lo que el mismo Atria llama la atención en su texto.

A mi juicio, y pienso que Gargarella coincidiría con esto, el argumento de Atria puede ser extrapolado para demostrar que cuestiones de justicia distributiva, i.e. cuestiones sobre cuáles son los criterios generales de tratamiento igualitario a ser utilizados en distribuciones entre los miembros de una comunidad, son cuestiones que no pueden ser jamás decididas por intermedio de argumentos puramente jurídicos. Para decir lo mismo con otras palabras: una forma de razonamiento que es orientada hacia la justicia entre privados (i.e. una justicia de tipo correctivo) no puede ser utilizada como forma de razonamiento para la realización de la justicia distributiva.

El principal punto que queda pendiente es, por tanto, la posibilidad de extrapolar el argumento de Atria a otros derechos fundamentales, una radicalización que podría ser explorada en más detalle tanto por aquellos que esencialmente difieren de su argumento (como Bernal y Cruz) cuanto por él mismo. 
Esto sugiere una controversia aun más abstracta. La idea misma de derecho subjetivo es profundamente controvertida. Hay aquellos que, como Villey, MacIntyre y Simone Weil, piensan que ella es políticamente perniciosa. Atria llega a tocar el problema al final de su artículo. Mas el tema demandaría, creo yo, un estudio más complejo que tendría directas implicaciones para el debate sobre los derechos sociales.

7. Quien escribe la introducción a una obra colectiva, como son las revistas científicas, recibe visitantes en una casa que no construyó. Los verdaderos constructores pueden pensar que su comprensión de la importancia de las partes individuales de esta casa es excéntrica o incorrecta. Por eso, es posible que Atria, Bernal, Cruz o Gargarella no acepten mi visión sobre lo que es esencial en el debate promovido en este número de Discusiones. Ellos quizás piensen que alguna parte esencial de sus argumentos fue ignorada o deformada en esta introducción. Mi sola disculpa por estos errores sería el hecho de que los argumentos presentados son a un tiempo complejos y eruditos.

La complejidad de los argumentos, la sutileza de la percepción que subyace a éstos, y la claridad en su presentación, son la medida del valor de los ensayos que siguen. 